\title{
Forging an ethical pathway: Disability accommodation, diverse voices, and standards of care
}

\author{
SATENDRA SINGH, LISA M MEEKS, UPREET DHALIWAL
}

\author{
"I have less eyesight than most, but I have more insight than many." \\ - Alexandra Adams (The Times, Sept 29, 2019)
}

The opening quote by Alexandra Adams, the first deaf-blind medical student in the United Kingdom, is a response to naysayers on her decision to join medicine. The cover page of this issue of IJME also highlights the underrepresented in medicine: portraying a healthcare professional with an acquired visual impairment who works with full professional rigour and dedication.

This disability themed issue is timely. Our world, and the practice of medicine, has forever been changed by recent events. Multiple challenges ensue as the syndemic of COVID-19 intersects with existing health disparities. Viewing health and illness through the lens of these disparities is important if marginalised communities are to experience health equity.

The articles in this issue address many concerns: lack of access to health professions education for people with disability; threats to the autonomy of women who might carry babies with chromosomal anomalies; giving voice to parents of children with disabilities and activists; and ethical concerns when physicians' organisations promote investigations that offer little benefit merely to guard against litigation. The articles draw on literature that highlights how global efforts are aligning to ensure equal access to education and healthcare for traditionally marginalised populations. The need to address disability-related issues, whether for patient or provider, is a societal imperative. The goal of equivalent and culturally relevant care necessitates a dialogue between diverse opinions and experiences.

\section{Disability accommodation}

This global practice removes barriers, allowing individuals with disability an opportunity to participate in educational, employment and social events. Accommodations are carefully constructed to uphold the academic standards or employment requirements of an organisation. While the route to achieving a standard may look different, the end goal or requirement remains the same. The most formidable barrier to disability inclusion, however, is attitudinal. In these cases, education is required. Two of the articles in this issue focus on education: one, on the perception of ability for learners with Colour Vision Deficiency (CVD), the other, on the restrictive and arbitrary requirements for admission to nursing programmes.

The way we see things, literally and figuratively, is the focus of Dhaliwal and colleagues' article (1). The authors engaged physicians across specialties to ascertain whether they felt learners with CVD should enter medical training. The perceptions of study participants regarding CVD ran the gamut: from incompatibility with medical training to confidence in the ability of individuals with CVD to practise medicine. Some believed that colour was paramount to the practice of medicine, despite the evidence that automation and audible signaling and attention to structure/pattern can eliminate a clinician's reliance on colour, allowing them to develop compensatory strategies that facilitate the safe practice of medicine.

The authors question whether learners and physicians with CVD are dangerous to patient well-being, or if these fears are unfounded. They point to the lack of empirical evidence showing any such harm. The silence of the Medical Council of India $(\mathrm{MCl})$ on this issue leaves learners to navigate uncharted territory where any disclosure of CVD may result in barriers to graduate

Authors: Satendra Singh (corresponding author - dr.satendra@gmail.com), Associate Professor, Dept of Physiology, and Health Humanities Group, University College of Medical Sciences, Delhi, INDIA; Lisa M Meeks (meeksli@med.umich.edu), Assistant Professor of Family Medicine, University of Michigan Medical School, Michigan, and Researcher, Center for a Diverse Healthcare Workforce, University of California, Davis School of Medicine, California, USA; Upreet Dhaliwal (upreetdhaliwal@yahoo.com), Former Director-Professor, Dept of Ophthalmology, and Health Humanities Group, University College of Medical Sciences, Delhi, INDIA.

To cite: Singh S, Meeks LM, Dhaliwal U. Forging an ethical pathway: Disability accommodation, diverse voices, and standards of care. Indian J Med

Ethics. 2020 Oct-Dec; 5(4) NS: 264-7 DOI:10.20529/IJME.2020.109.

CIndian Journal of Medical Ethics 2020 
training.

A middle ground, where decision-making is more informed, and is led by disability and assistive technology experts who can thoughtfully evaluate concerns within areas of specialties and suggest validated accommodations, would be ideal. Indeed, the literature shows that attention to shading versus colour, to patients' symptoms, to touch and transparency, and cross-checking with another medical professional (or the patient) are known workarounds in CVD (2). Compensatory time as an accommodation is also appropriate when the activity is not time-dependent or life threatening. Additional accommodations, like coloured overlays, specialised glasses or color converting software can also eliminate barriers caused by CVD (2). Finally, awareness and education about CVD, and proactive planning in health professions education are critical for learners and professors alike.

The paper by Angothu and colleagues discusses barriers to entry in nursing school and argues that the disparate approaches to disability inclusion between the $\mathrm{MCl}$ and the Indian Nursing Council (INC), prevent qualified learners with disabilities from entering the nursing profession in the same proportion as do physicians with disabilities (3). With a global "shortfall" of almost 15 million healthcare workers in 2030 (4), active barring of qualified candidates with disabilities is a public health concern. The author refers to the ability of nurses with disabilities to contribute to many forms of nursing including public health promotion, disease prevention, rehabilitation, and preventative care. Indeed, there are many stories of success for those with disabilities, including those with missing limbs, learning disabilities, and chronic health conditions, in addition to those already considered eligible under the governing laws (5). Despite a stated commitment by the government to allowing disabled candidates, up to at least 5\%, into nursing, the authors argue that the arbitrary assignment of impairment-based restrictions limits the inclusion to those with lower limb disabilities of $40-50 \%$.

The exclusion of specific categories of disability, as well as the simplistic assignment of allowable impairment takes a reductionist view of disability, negating the benefits inherent in the lived experience of disability. The authors contend that the INC should adopt a more pragmatic, social justice view of nurses with disabilities, while developing updated inclusion and exclusion criteria for admissions by involving multiple stakeholders. They posit that a committee of disabled healthcare providers with knowledge of specialised equipment and advanced technology could help innovate and identify mechanisms and accommodations. Relying on the social model of disability would allow for greater inclusion, for informed guidelines, periodic programme review, and could help dismantle attitudinal barriers.

These actions may result in representation that more closely aligns with the intention of the Rights of Persons with Disabilities Act, 2016 (RPDA). We propose that national guidelines must be set and that global commitments to disability inclusion in health professions education can provide long-term stability and accountability in decision-making on reasonable and appropriate accommodations for learners with disability.

\section{Diverse voices and advocacy}

Breimer, in his article on Non-invasive Prenatal Testing (NIPT) to detect Down Syndrome (DS) laments that while screening to detect neural tube defect-affected pregnancies was welcomed, NIPT to accurately predict the chance of aneuploidy (trisomies) has met with opposition from what he calls 'Special Interest Groups' (6). These include the guardians of children with DS and also disability activists, who fear that privileges for children with DS may depreciate if the condition becomes preventable through abortions. Breimer suggests that their fear must not upstage the autonomy of pregnant women to choose the best interests for their own families, considering the costs and other burdens of raising a child with multiple disabilities.

Not long ago, Bennett and Harris contended that prospective parents have an ethical commitment to avoid disability (7). Sally Phillips, the English actress and mother of a child with DS, while addressing the World Congress of Royal College of Obstetricians and Gynaecologists, emphasised, "We know you didn't go into medicine to cause harm, but...intentionally or not, [the] harm is being done to us...In those hospitals which offer NIPT, the DS live birth rate is down $30 \%$, in those...that do not...it is down 9\%." (8).

Recently, the apex Court in India allowed a woman in Mumbai, who was carrying twins, to medically terminate one of the foetuses as it had DS (9). This is the first time a court has allowed selective reduction among twin foetuses. Their decision was guided by the foetal medicine specialist whose recommendation was largely based on the medical model of disability. The judgement quotes (9):"Note on trisomy 21 (Down Syndrome): This is a chromosomal abnormality and has no treatment. The baby will suffer from significant mental retardation (sic), intellectual disability and may also have other health conditions like heart disease etc. in the affected person. Thus, leading to severe limitations on the patient who needs a [full time] caregiver and causes mental, logistical and financial challenges to the parents."

This negative view of disability is countered by Owen et al, who dispute the notion that congenital disability (in this case, DS) is invariably burdensome - indeed, as others also attest, the negativity is misplaced in many cases (10). Breimer argues that if fewer DS children are brought into the world, society could satisfactorily guarantee secure funding for those influenced by the condition (6); however, an important viewpoint is missing in his commentary - that of the caregivers with lived experiences, and 
of disability advocates.

As Owen et al point out, disability activists are not the enemy, but are voices that must be heard if one is to offer NIPT in an ethical way with a fully framed informed consent and respecting the autonomy of pregnant women (10). Activists fear that physicians may not be the right people to inform women about the consequences of giving birth to a child with DS because many would not have the lived experience (11). Moreover, physicians are known to be biased against bringing babies with anomalies into the world, and this might influence the nature of the informed consent (12). There are challenges that need to be addressed before prenatal testing can be considered without ethical qualms - it would be of benefit to hear the diverse voices of all stakeholders. Adrienne Asch, a bioethicist with disability, first raised the issue of exclusion of voices with disabilities in matters pertaining to them. Her pioneering work created a ripple effect so that bioethicists and researchers started engaging with people with disabilities (13).

In India, professional guidance on NIPT is lacking. There is an ethical distinction between offering NIPT routinely or as an opt-in. While the latter depends on personal values, the former points to the inherent devaluation of a person with DS by society, and reflects the wish to encourage/promote a certain type of unborn child (one who is not "disabled"). Many disability activists argue that it is akin to eugenics (10).

\section{Ethical standards of care}

Sartwelle et al, with reference to electronic foetal monitoring (EFM) and cerebral palsy (CP), demonstrate how - behind the facade of patient-centred medicine - the threat of litigation can drive decision-making (14). They suggest that standards of care are abrogated by physicians who consider EFM as a means to prevent CP since research shows it is not superior to manual methods in monitoring foetal heart rates, but can harm when it leads to unnecessary surgical interventions. The paper highlights the conflict between a physician's desire for safeguards against litigation and the desire to provide safe care to the patient. As long as a procedure is propagated by a scientific body as being an acceptable "standard of care", it can be expected that a "reasonably prudent" physician will perform it using a "reasonable amount of skill and care", whatever their personal understanding of the evidence (15). The factors that help keep a redundant procedure/investigation going include the fear of litigation, but also the horror of potentially being responsible for an adverse outcome, besides monetary gain (16). Disciplines must periodically redefine standards of care based on new peer-reviewed evidence. Individual physicians, too, rather than practising "defensive medicine", should advocate for ethical and evidence-based standards of care, and for reform of litigation laws.

\section{The role of educationists, health professions councils, the legislature, and governments}

Last year, the United Nations (UN) Committee on the Rights of Persons with Disabilities criticised India's Country Report on the implementation of the Convention on the Rights of Persons with Disabilities (CRPD) for its adherence to the medical model of disability (17), and recommended "bringing the guidelines for assessing and certifying disability into line with the human rights model of disability, ensuring that organizations of persons with disabilities are involved in the reform of these guidelines."

The judgment on the termination of one of the foetuses with DS paid scant attention to the UNCRPD recommendations (9). Article 5 of the UNCRPD mandates that "States Parties shall prohibit all discrimination on the basis of disability and guarantee to persons with disabilities equal and effective legal protection against discrimination on all grounds" (18). Unfortunately, disability laws in the UK (Equality Act, 2010) and in India (RPDA, 2016) have twisted Article 5 to condone such discrimination if it is shown that the "impugned act or omission is a proportionate means of achieving a legitimate aim" (19). Such riders make it difficult to achieve reasonable accommodation as it is subject to bureaucratic interpretation. This was criticised by the UN Committee; they recommended that the Constitution be amended to explicitly prohibit disability-based discrimination and section 3(3) be repealed (17).

These recommendations must percolate down to all decision-making bodies, to educational institutes, including those where all learners, regardless of disability status, are being trained to care for the health of all people, including those with disabilities, in the communities where they live and work.

The General Medical Council, UK, involved people with disabilities while preparing guidance for learners with disabilities in medical education, making them feel 'Welcomed and valued' (20), as did the Association of American Medical Colleges in the United States (21). The MCI did not (20). With the enactment of the National Medical Commission in place of the now dissolved $\mathrm{MCl}$, India has a new apex regulator for medical education; hopefully they will adopt uniform standards that will keep pace with global reforms.

Multiple countries have addressed disability inclusion in health professions education, yet no one standard has been adopted or created to date. The creation of an International Council on Inclusive Medical Education moves us towards the framing of global standards on disability accommodation (22). The Council's aim is to guide the creation of a shared vision of equality and of 
disability-informed medicine. Combining guidance from individual countries, it will help formulate an international benchmark of standards to serve as a roadmap for countries seeking to create accessible health professions programmes and practice (22). With the advent of this Council, international guidance will become available and arbitrary decisions about the level or type of disability deemed "acceptable" for health professions education can be challenged using the international standards. These standards will serve as a global "call to action and education" on disability accommodation and inclusive practices for health professions education.

\section{Conclusions}

The UN recommendations testify to the importance of considering disability as a human rights issue and curriculum designers must respect the lived experiences of health professionals with disabilities while bringing in reforms. There are limits to which any law can fully impact inclusion; thus, advocacy for the profession requires a plea to the hearts of programmes, and not simply to the minds. Embracing differences is difficult when one is not fully educated on the topic, and is, therefore, reliant on the stereotypes that are socially created to inform the work. We have to actively fight against these deeply ingrained constructs of what it means not only to be disabled, but also to be abled.

\section{References}

1. Dhaliwal U, Singh S, Nagpal G, Kakkar A. Perceptions of specialist doctors of the ability of doctors with colour vision deficiency to practise their specialty safely. Indian J Med Ethics. 2020 Oct-Dec;5(4)NS: 268-77. DOI: 10.20529/IJME.2020.110.

2. Meeks LM, Jain NR, Herzer KR. Universal design: Supporting students with color vision deficiency (CVD) in medical education.J Postsecond Educ Disabil. 2016;29(3):303-9.

3. Angothu H, Philip S, Somanathan R, Reddy KS, Jayarajan D, Muliyala KP, Thirthahalli J. Admission of persons with disabilities into nursing and midwifery professional courses: Progress made by the Indian Nursing Council. Indian J Med Ethics. 2020 Oct-Dec; 5(4)NS: 277-85. DOI:10.20529/IJME.2020.111.

4. United Nations. Transforming our world: the 2030 Agenda for Sustainable Development. Geneva: United Nations; 2015.

5. Meeks LM, Herzer K, Jain NR. Removing barriers and facilitating access: Increasing the number of physicians with disabilities. Acad Med. 2018; 93(4):540-3.

6. Breimer LH. Non-invasive prenatal testing: Special interest groups vs women's autonomy. Indian J Med Ethics. 2020 Oct-Dec;5(4)NS: 285-90 DOI:https:// doi.org/10.20529/JMME.2020.069.

7. Bennett R, Harris J. Are there lives not worth living? When is it morally wrong to reproduce? In: Dickenson D, editor. Ethical issues in maternal-fetal medicine. Cambridge: Cambridge University Press; 2002:321-34.

8. Down Syndrome Research Foundation, UK. Sally Phillips' address to the Royal College of Gynaecologists World Congress; 2019 Jun 20 [cited 2020 Oct 6] Available from: https://www.dsrf-uk.org/sally-phillips-rcog19/

9. Supreme Court of India. Komal Hiwale vs State of Maharashtra: SLP(C) No. 7379 of 2020. [cited 2020 Oct 6]. Available from: https://indiankanoon.org/ doc/50273090/

10. Owen A, Singh S, Kirschner KL. Disability activism and non-invasive prenatal testing: A response to Breimer. Indian J Med Ethics. 2020 Oct-Dec; 5(4) NS: 290-3. DOI:10.20529/IJME.2020.112.

11. How B, Smidt A, Wilson NJ, Barton R, Valentin C.'We would have missed out so much had we terminated': What fathers of a child with Down syndrome think about current non-invasive prenatal testing for Down syndrome. J Intellect Disabil. 2019 Sep; 23(3):290-309.

12. Valentin C, Smidt A, Barton R, Wilson NJ, How B. Mothers of a child with Down syndrome: A qualitative analysis of the perspectives on non-invasive prenatal testing. Midwifery. 2019;76:118-24.

13. Roberts D. Adrienne Asch (1946-2013). Nature. 2013 Dec 19;504(7480):377. doi: 10.1038/504377a

14. Sartwelle TP, Johnston JC, Arda B, Zebenigus M. Cerebral palsy litigation after fifty years: a hoax on you. Indian J Med Ethics. 2020 Oct-Dec; 5(4)NS:295-301 DOI: https://doi.org/10.20529/IJME.2020.093. Epub 2020 Sep 5.

15. Kelly AM. Medical experts and evaluations of the Standard of Care in medical litigation - strengths, weaknesses and potential improvements.J Law Med. 2019;27(2):455-71.

16. Jordan JE, Flanders AE. Headache and neuroimaging: why we continue to do it. AJNR Am J Neuroradiol. 2020; 41(7):1149-55.

17. United Nations Digital Library. Concluding observations on the initial report of India:Committee on the Rights of Persons with Disabilities. 2019 Sep 12 [cited 2020 July 25]. Available from: https://digitallibrary.un.org/record/3848327? In=en

18. United Nations Department of Economic and Social Affairs. Convention on the Rights of Persons with Disabilities (CRPD). 2006 [cited 2020 Oct 6]. Available from: https://www.un.org/development/desa/disabilities/convention-on-the-rights-of-persons-with-disabilities.html.

19. Nair S. The amendments to Disability Bill: what they are, what they will do. Indian express.com. 2016 Dec 13 [cited 2020 Oct 6]. Available from: https:// indianexpress.com/article/explained/disabilities-bill-amendment-discrimination-against-differently-abled-4424039/

20. Singh S. Medical Council of India's new guidelines on admission of persons with specified disabilities: Unfair, discriminatory and unlawful. Indian J Med Ethics. 2019 Jan-Mar; 4(1):29-34. DOI: 10.20529/JME.2018.064.

21. Meeks LM, Jain NR. Accessibility, inclusion, and action in medical education:lived experiences of learners and physicians with disabilities. Washington, DC: Association of American Medical Colleges; 2018 [cited 2020 Oct 6] Available from: https://sds.ucsf.edu/sites/g/files/tkssra2986/f/aamc-ucsf-disabilityspecial-report-accessible.pdf.

22. Meeks LM, Maraki I, Singh S, Curry RH. Global commitments to disability inclusion in health professions. Lancet. 2020; 395(10227):852-3. 